\title{
Use of neutral plasma coagulation in groin node dissection for vulvar malignancy: a novel technique
}

\author{
This article was published in the following Dove Press journal: \\ Cancer Management and Research \\ 5 July 2011 \\ Number of times this article has been viewed
}

\author{
Thumuluru Kavitha Madhuri \\ Anil Tailor \\ Simon Butler-Manuel \\ Department of Gynaecological \\ Oncology, The Royal Surrey County \\ Hospital, Guildford, Surrey, UK
}

\begin{abstract}
Vulvar cancer is an uncommon disease with approximately 1000 cases reported annually in the UK. Lymph node involvement is an important prognostic indicator. Vulvectomy and bilateral groin node dissection are the preferred surgical treatments for early disease and increase survival. However, significant morbidity with lymphocyst formation and wound breakdown has been reported in more than $50 \%$ of cases. We report the first case following use of the PlasmaJet ${ }^{\mathbb{R}}$ neutral argon coagulation system to reduce postoperative lymphocyst formation.
\end{abstract}

Keywords: lymphocyst formation, wound, lymphodema

\section{Introduction}

Vulvar malignancy is the fourth most common malignancy of the female genital tract, accounting for less than 5\% of all gynecologic tumors worldwide. Of these, $85 \%$ are squamous cell in origin, and the average age at presentation is 65 years. Surgical excision achieves excellent local control and remains the mainstay of treatment. Surgical excision depends on the extent of disease and may be in the form of wide local excision or radical vulvectomy. Lymphadenectomy in the form of bilateral groin node dissection (BGND) is performed for all central tumors with depth of invasion greater than $1 \mathrm{~mm}$, unless there is significant comorbidity contraindicating this, but is known to cause significant postoperative morbidity. Immediate postoperative complications include breakdown and lymphocyst formation in more than $50 \%$ of cases. In our experience, management of the groin wound presents a greater clinical problem than the central excision wound. We report the first case of use of the PlasmaJet ${ }^{\circledR}(\mathrm{PJ})$ (Plasma Surgical Limited, Oxfordshire, UK) system following groin node dissection to prevent lymphocyst formation and wound complications.

\section{Case summary}

A 35-year-old multiparous lady with a body mass index of 25 was referred with a 2-month history of an itchy, vulvar lesion, which had increased from a pea-sized mass to $2.5 \mathrm{~cm}$, causing discomfort. She smoked ten cigarettes a day with an otherwise unremarkable medical history. The lesion surface appeared white with no evidence of bleeding or discharge. Examination under anesthetic revealed a $2.5 \times 2.5 \mathrm{~cm}$ ulcerated tumor with heaped edges and extending into the vagina at the posterior fourchette. It appeared mobile and clear of the anal sphincter. A wedge biopsy confirmed a welldifferentiated squamous cell carcinoma (SCC) to a depth of at least $1.2 \mathrm{~mm}$.
Correspondence: Thumuluru Kavitha Madhuri

Department of Gynaecological Oncology, The Royal Surrey County Hospital, Level B, GOPD, Egerton Road, Guildford, Surrey, GU2 7XX, UK

Tel +44 I 48357 I I 22 ext 2 I 76

Fax +44 I483 402742

Email docmadhuri23 I@doctors.org.uk 
Following review of the pathology at the gynecology and oncology multidisciplinary team meeting, a radical posterior vulvectomy with BGND was recommended. In consultation with the patient, discussion focused on the risks of possible nerve injury to branches of the femoral nerve leading to paresthesia, risk of lymphocyst, and subsequent lymphedema formation. The PJ device was discussed and consent obtained to explore its use in the possible reduction of lymphocyst formation. She underwent a radical posterior vulvectomy and BGND with sparing of the long saphenous vein (LSV) bilaterally. The technique involved a linear incision along the medial - four-fifths of a line between anterior superior iliac spine and pubic tubercle and $1 \mathrm{~cm}$ above and parallel to the groin crease. The incision was carried through the subcutaneous tissues to the superficial fascia. Fascia lata, sartorious muscle, and external oblique aponeurosis were easily identified. Femoral vessels and nerve sheath was identified. Both superficial and deep groups of nodes were taken out en-bloc down to the fascia overlying the adductor muscles, and the saphenous vein ligated at the apex of the femoral triangle at the point of entry into the femoral vein. The left groin dissection was performed first (Figure 1). Following this, the PJ was used on the left groin to seal the lymph vessels and channels at a setting of $40 \%$ by spraying the PJ over the entire exposed surgical field at a distance of $10 \mathrm{~mm}$ from the surface to the tip of the instrument. This step of the procedure took 5 minutes (Figure 2). Use of the PJ was limited to the left side only. Surgery to the right groin was otherwise identical. A redivac drain size 10 was left in both groins, and daily output was recorded by the nursing team (Table 1). Both patient and nursing staff (observers for drain measurement) were blinded to the side of PJ use.

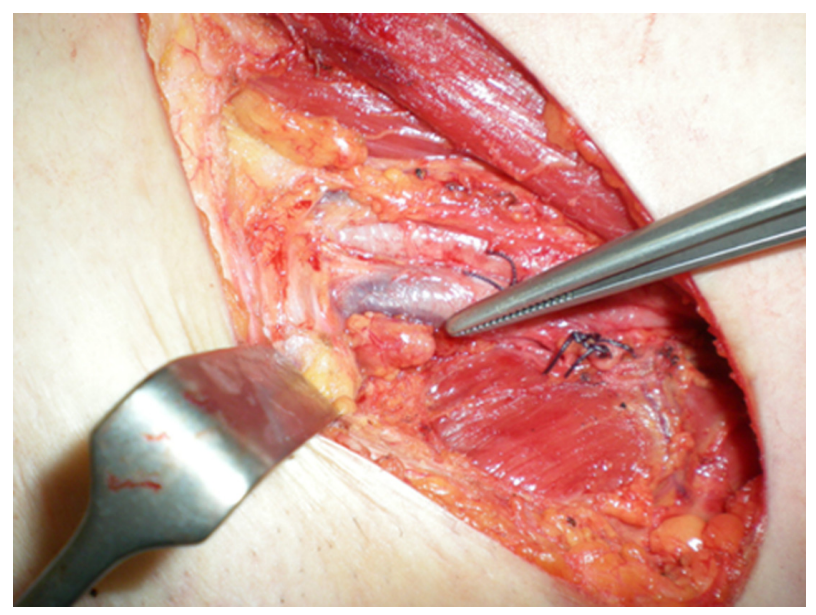

Figure I Groin node dissection with preservation of the saphenous vein.

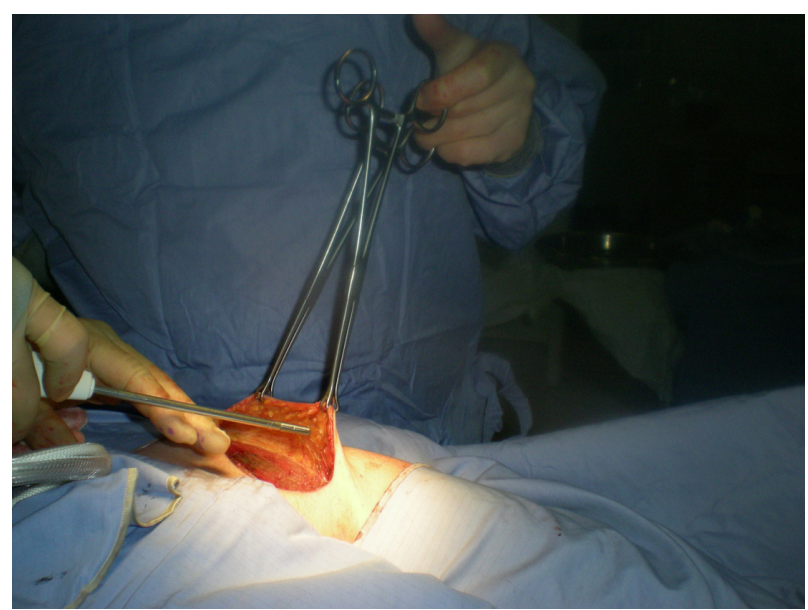

Figure 2 The Plasmajet ${ }^{\circledR}$ handpiece spraying neutral argon plasma to seal lymphatics following groin dissection.

The final histology confirmed a well-differentiated SCC with a maximum diameter of $27 \mathrm{~mm}$ and a maximum depth of $4 \mathrm{~mm}$. All the margins were clear and the deepest margin was $3 \mathrm{~mm}$. There was no evidence of lymphovascular space invasion. The eleven lymph nodes on the right and twelve on the left were uninvolved.

She was discharged 9 days postoperative with drains in situ and regular nursing support in the community. She attended a clinic 12 days later and the right groin had developed two separate tense lymphocysts at the medial and lateral aspects of the wound. The left groin appeared to be healing well with minimum drain output and hence the drain was removed. The right drain continued to produce significant volumes of fluid and was removed only when she was reviewed on day 35, when the lateral lymphocyst appeared to have resolved and the medial lymphocyst also appeared to have reduced in size. At clinic review 18 months postoperative, the patient reported swelling of the right leg. Clinically, she had lymphedema grade 2 in the right lower limb to the level of the thigh. The left lower limb appeared to be normal. Following referral to a therapist, she was managed with manual lymphatic drainage and support hosiery.

Table I Daily drain outputs following bilateral groin node dissection

\begin{tabular}{lll}
\hline Day postoperative & Left & Right \\
\hline I & 100 & 20 \\
2 & 60 & 300 \\
3 & 40 & 80 \\
4 & 110 & 160 \\
5 & 85 & 130 \\
6 & 60 & 140 \\
7 & 20 & 60 \\
Total output & 485 & 950 \\
\hline
\end{tabular}




\section{Discussion}

The primary treatment modality for vulvar cancer remains surgery. Basset in 1912, and subsequently Taussig and Way in the 1940s, described en-bloc dissection involving the butterfly technique. ${ }^{1}$ This increased 5-year survival rates to around $90 \%$ in stage 1 patients and an overall survival of $70 \%$ but resulted in prolonged hospitalization and complications due to wound breakdown and lymphedema, leading to significant morbidity. ${ }^{1,2}$ In 1962, Byron described the triple incision technique that was later popularized by Hacker et al and Di Saia and Creasman. ${ }^{2,3}$ Morbidity following the triple incision technique surgery is much lower, though is still significant with wound breakdown, seroma formation, and lymphedema reported in more than $50 \%$ of cases. Gaarenstroom et al reported one or more postoperative complications in $76 \%$ of treated cases leading to protracted hospital stay, psychosexual disturbances, negative body image, and lymphedema. ${ }^{5}$ Rouzier et al suggested modified techniques, including sartorius transposition, preservation of fascia lata, and LSV, but concluded that transposition of sartorius did not decrease morbidity, though better outcomes were noted with preservation of fascia lata and saphenous vein.?

Two subsequent Gynecologic Oncology Group studies have demonstrated a $33 \%$ fall in postoperative complications when preserving the LSV but have also highlighted that use of fibrin sealants did not reduce lymphedema rates and also increased the risk of central wound complications. ${ }^{4-8}$

Sentinel lymph node procedure (SLN) or vulvar cancer in the UK is being performed as part of GROINSS-V II (Groningen International Study on Sentinel Nodes in Vulvar Cancer), which is evaluating the short- and long-term morbidity associated with SLN biopsy and the safety of replacing inguinofemoral lymphadenectomy in patients with negative sentinel node or metastasis less than $2 \mathrm{~mm}$. At the time of this case, our center was not recruiting to this study.

The PJ is a novel device that produces a jet of pure argon plasma by heating pressurized argon gas. Energy from the argon plasma transfers to tissue as light, heat, and kinetic energy. It is rapidly dissipated, generating very limited lateral thermal damage. The light produced is in the visible and near ultraviolet parts of the spectrum, illuminates the operative field, and helps to indicate the position of the jet. Iannelli et al reported use of the PJ device in abdominoplasty and found reduced drain output and fluid output. ${ }^{6}$ This case demonstrates reduced daily drain outputs and no lymphocyst formation on the groin wound treated with PJ. Lymphedema was only reported on the contralateral side where the PJ was not used.

This case suggests a possible role for the PJ system to reduce postoperative wound complications following BGND, which needs to be explored further. Following ethical approval, we are currently undertaking a prospective, crossover, doubleblind, randomized, control trial to assess the PJ system, with the primary outcome being the possibility of reduction in wound breakdown and lymphocyst and lymphedema formation following BGND for vulvar cancer.

\section{Disclosure}

The device and handpiece were provided free of charge for this case report.

\section{References}

1. Morgan MA, Mikuta JJ. Surgical management of vulvar cancer. Semin Surg Oncol. 1999;17:168-172.

2. Hacker NF, Leuchter RS, Berek JS, et al. Radical vulvectomy and bilateral inguinal lymphadenectomy through separate groin incisions. Obstet Gynecol. 1981;58:574-579.

3. Di Saia PJ, Creasman WT. Clinical Gynecologic Oncology, St Louis MO Mosby-Year Book; 1993.

4. Carlson JW, Kauderer J, Walker JL, et al. A randomized phase III trial of VH fibrin sealant to reduce lymphedema after inguinal lymph node dissection: a Gynecologic Oncology Group study. Gynecologic Oncology. 2008;110:76-82.

5. Gaarenstroom KN, Kenter GG, Trimbos JB, et al. Postoperative complications after vulvectomy and inguinofemoral lymphadenectomy using separate groin incisions. Int $J$ Gynecol Cancer. 2003;13:522-527

6. Iannelli A, Schneck AS, Gugenheim J. Use of the PlasmaJet ${ }^{\circledR}$ system in patients undergoing abdominal lipectomy following massive weight loss: a randomized controlled trial. Obes Surg. 2010;20:1442-1447.

7. Rouzier R, Haddad B, Dubernard G, et al. Inguinofemoral dissection for carcinoma of the vulva: effect of modifications of extent and technique on morbidity and survival. J Am Coll Surg. 2003;196:442-450.

8. Zhang SH, Sood AK, Sorosky JI, et al. Preservation of the saphenous vein during inguinal lymphadenectomy decreases morbidity in patients with carcinoma of the vulva. Cancer. 2000;89:1520-1525.
Cancer Management and Research

\section{Publish your work in this journal}

Cancer Management and Research is an international, peer-reviewed open access journal focusing on cancer research and the optimal use of preventative and integrated treatment interventions to achieve improved outcomes, enhanced survival and quality of life for the cancer patient The journal welcomes original research, clinical \& epidemiological

\section{Dovepress}

studies, reviews \& evaluations, guidelines, expert opinion \& commentary, case reports \& extended reports. The manuscript management system is completely online and includes a very quick and fair peerreview system, which is all easy to use. Visit http://www.dovepress.com/ testimonials.php to read real quotes from published authors. 